\title{
Und täglich grüßt die Krise
}

\section{Liebe Leserin, lieber Leser,}

wir bewegen uns gerade zielsicher von einer Krise in die nächste. Erst standen die Bänder wegen der Corona-Pandemie still, was dazu führte, dass weniger Halbleiter bestellt wurden. Dann blockierte ein Schiff eine der wichtigsten Schifffahrtsrouten der Welt. Und nun musste man feststellen, dass auch eine wieder anlaufende Industrie nicht beliebig viele Teile sofort liefern kann - erst recht nicht, wenn der Produktionsstandort auf der anderen Seite der Welt liegt.

Schon in Krise eins wurde ersichtlich: Die Lieferketten sind zu lang. Geändert aber hat sich nichts. In Krise zwei gelangte man zur Erkenntnis: Wenige Transportwege sind problematisch. Wieder änderte sich nichts. Und jetzt möchten alle zugleich die Menge an Teilen, die man während der ersten Krise abbestellt hatte, und noch mehr und am besten sofort? Wenig überraschend funktioniert das nicht, aber wieder ist das nur ein Teil des Problems, schließlich war Lagerhaltung von Bauteilen in den vergangenen Jahren verpönt, Just-in-Time-Produktion hingegen galt als der heilige Gral einer effizienten Industrie. Dass hier ein einziger Flaschenhals schon die Produktion zum Erliegen bringen kann, war auch den begeistertsten Befürwortern bewusst; dass es gleich an drei Stellen hapern könnte, vermuteten dagegen nicht einmal die schärfsten Kritiker.

Jetzt passierte, was wirklich niemand will, also zum dritten Mal: Ein winziges Bauteil lässt die Bänder stillstehen, sorgt sogar für die Schließung ganzer
Werke. Wie wir alle wissen, funktionieren Provisorien meist deutlich besser als vermutet. Die Sorge darum, ob die Anlagen auch nach der Krise dauerhaft stillstehen, ist durchaus berechtigt.

Auch den Hinweis darauf, dass die Krisen hausgemacht sind, die Folgen absehbar waren und sich jetzt eigentlich niemand wirklich beschweren darf, muss sich unsere Wirtschaft gefallen lassen. Jetzt, da kurz hintereinander mehrere als unwahrscheinlich betrachtete Eventualitäten eingetreten sind, wäre es endlich an der Zeit, die Konzepte zu überarbeiten. Die Transformation ist ohnehin voll im Gang, die Gelegenheit also günstig.

Viel Vergnügen, bei der Lektüre dieser Ausgabe der MTZ.

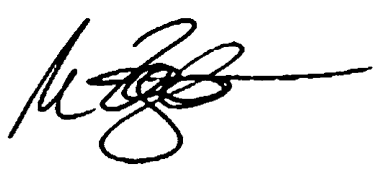

Marc Ziegler

Stellvertretender Chefredakteur

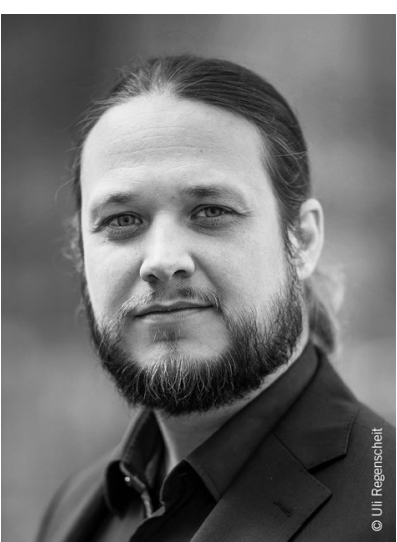

